\title{
PARTICIPAÇÃO SOCIAL e deMOCRÁtica no PARLASUL
}

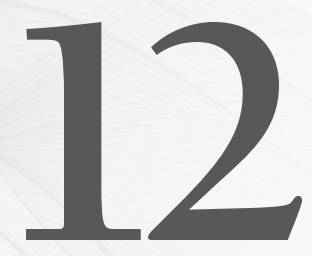

\section{Luana Paixão Dantas do Rosário}

Mestre e Doutoranda e em Direito Público pela UFBA. Especialista em Direito do Estado pela Unyahna/JusPodivm. Coordenadora da Pesquisa e Extensão do Curso de Direito da Faculdade de Tecnologia e Ciência. Professora visitante nos Cursos de Especialização da UFBA e Universidade Católica de Salvador. Professora de Direito Municipal, Filosofia Jurídica, Hermenêutica Jurídica, Direito Constitucional e Projeto de Pesquisa, na Faculdade de Tecnologia e Ciência. Advogada.

\section{Rogério Silva de Magalhães Castro}

Graduando em Direito pela Faculdade de Tecnologia e Ciências. Estagiário.

Recebido em: 17.08.2011

Aprovado em: 31.08.2011

ÁREA Do DIREITO: Internacional

Resumo: 0 objetivo deste trabalho será refletir acerca do papel do Parlasul no processo de integração política intentada pelo Mercosul. Questionar-se-á a sua natureza de órgão legislativo comunitário, sua legitimidade e as possibilidades de participação social e democrática no seu âmbito. Para este fim, abordar-se-á a definição de integração política regional e representatividade neste âmbito, a crise da democracia representativa, a despolitização marcante da pós-modernidade e as transformações do cenário político em tempos de globalização e supranacionalização. Propor-se-á a tolerância como vetor imprescindivel à realização da verdadeira integração. Comparar-se-á a proposta do Parlasul com a
ABSTRACT: This paper will reflect on the role of Parlasur in the process of political integration brought by Mercosur. Questioning will be the nature of the legislation, its legitimacy and the possibilities of social participation and democratic in its scope. To this end, it will address the definition of political integration and regional representation in this context, the crisis of representative democracy, marked the depoliticization of postmodernity and transformations of the political landscape in times of globalization and supranationalisation. Propose will be the tolerance vector as essential to the achievement of true integration. It will compare the proposed Parlasur with the 
experiência do Parlamento Europeu. A relevância teórica do tema exurge da necessidade de compreensão do modelo de integração política, social e cultural desenvolvida por blocos regionais, em específico, o Mercosul. A relevância prática advém da necessidade de reflexão deste modelo e detecção de eventuais necessidades de correção. 0 método empregado será o proposto pela fenomenologia, precário e provisório, pelo qual o tema será apreendido em sua complexidade, porém não em sua totalidade.

Palavras-chave: Democracia - Participação Supranacionalização - Mercosul - Parlasul. experience of the European Parliament. The theoretical relevance of the theme exurge the need for understanding the model of political, social and cultural developed by regional blocs, in particular, Mercosur. The practical importance stems from the need to reflect this model and identify possible needs correction. The method employed is that proposed by phenomenology, precarious and provisional, for which the theme will be seized in its complexity, but not in its entirety.

KeYwords: Democracy - Participation - Supranationalization - Mercosur - Parlasur.

SumÁRIO: 1. Introdução - 2. Definição de política, integração política regional e pós-modernidade - 3. 0 Parlasul no processo de integração política do Mercosul: 3.1 Da Comissão Parlamentar Conjunta ao Parlasul; 3.2 Composição e estrutura; 3.3 Funções e princípios - 4. Discussões acerca da natureza parlamentar do Parlasul: 4.1 Análise comparativa entre 0 Parlasul e o Parlamento Europeu - 5. A participação social e democrática no Parlasul - 6. Conclusão - 7. Referências.

\section{INTRODUÇÃO}

Ultrapassada a fase inicial de integração preponderantemente econômica que faz surgir os blocos de integração regional, estes ingressam na nova fase de integração política, social e cultural. Entretanto, há advertências de que este processo de integração política esteja acontecendo com um acentuado grau de déficit de legitimidade e participação popular. A integração política no âmbito comunitário seria mais uma realização dos governos do que um processo ativo e verdadeiro de cidadania.

O objetivo deste trabalho será refletir acerca do papel do Parlasul no processo de integração política intentada pelo Mercosul. Questionar-se-á a sua natureza de órgão legislativo comunitário, sua legitimidade e as possibilidades de participação social e democrática no seu âmbito. Para este fim, abordar-se-á a definição de integração política regional e representatividade neste âmbito, a crise da democracia representativa, a despolitização marcante da pós-modernidade e as transformações do cenário político em tempos de globalização e supranacionalização. Propor-se-á a tolerância como vetor imprescindível à realização da verdadeira integração. 
A relevância teórica do tema exurge da necessidade de compreensão do modelo da integração política, social e cultural que vem sendo desenvolvida por blocos regionais, em específico, o Mercosul. A relevância prática advém da necessidade de reflexão deste modelo e detecção de eventuais necessidades de correção.

O método empregado será o proposto pela fenomenologia, que, precário e provisório, entende o tema de conhecimento como fenômeno, a ser apreendido em sua complexidade, porém não em sua totalidade, não como um dado que se coloca à consciência, mas, como um construído da intencionalidade de quem se predipõe a conhecer, no desentranhamento de uma de suas possibilidades. ${ }^{1}$ Ressalte-se que objeto de estudo será apreendido hermeneuticamente em suas dimensões política e jurídica, indissociáveis.

\section{DefiniçÃo de POLÍtiCA, INTEGRAÇÃO POLítiCA REgIONAL E PÓS- MODERNIDADE}

Segundo Bittar, o termo política, do grego politiké, advém da polis grega, enquanto epolistés remete a ideia de cidadão. Portanto, a origem etimológica destas expressões demonstra que, em essência, o poder político é aquele que se volta à coletividade, e que, para além do governo, abrange as escolhas do que é conveniente para o homem da polis. Portanto, a política tem relação com os modos de organização do espaço público, objetivando o convívio social. ${ }^{2}$

Tem relação, também, com as formas de gerenciamento da coisa pública, dos recursos a ela ligados, com as estratégias de definição de critérios para o alcance de fins comuns, com a eleição das molas propulsoras do desenvolvimento social, com a definição de ideologias predominantes na constituição da arquitetura da sociedade. Mais que tudo, política tem relação com distribuição do poder, pois, entre governantes e governados, uns estão incumbidos de distribuir para os outros. ${ }^{3}$

Aristóteles, na Ética a Nicômaco, afirma que a política é a ciência dos fins para a felicidade humana, pois, apesar de todas as ciências possuírem uma finalidade, a política se torna plural a ponto de abranger a finalidade de todas as outras e ainda disciplinar o agir do homem como ser inserido na comunidade

1. Sobre o método, ver: Oliveira. Decisão judicial e o conceito de princípio. A hermenêutica e a (in)determinação do direito. Porto Alegre: Livraria do Advogado, 2008.

2. Bittar; Almeida. Curso de filosofia política. 3. ed. São Paulo: Atlas, 2007. p. 12.

3. Idem, ibidem. 
política. Para o estagirita, a felicidade constitui-se como maior bem da comunidade política e se traduz no agir segundo as qualidades éticas e no exercício perfeito destas. A diferença da participação dos homens na felicidade e a diferença da forma de buscá-las é a causa das formas de governo diversas. ${ }^{4}$ Enfim, para Aristóteles, a felicidade consiste numa certa maneira de viver no meio que circunda o homem, nos costumes e nas instituições adotadas pela comunidade à qual pertence.

O espaço político é espaço do comum (koinós) e não do privado (idíon). Entretanto, na atualidade, tem sofrido o esvaziamento de seu significado. Pesquisas demonstram a ausência de consciência cívica. No Brasil, o Indice de Participação Popular, criado pela Rede Interamericana para a Democracia, numa escala de 0 a 20, é de irrissórios 1,7. A realidade é de apatia da consciência política popular e de frágil participação política popular. ${ }^{5}$

Bittar ressalta que no contexto pós-moderno impera a multiplicação dos modos individualistas de ação, formas de comportamento que determinam o isolamento dos agentes sociais e a dissolução do corpo de objetivos que movimentam as decisões políticas. A política, com isto, perde sentido, ganhando significação o imperativo do mercado, que, com sua lógica de satisfação de interesses pessoais e privados, toma conta dos espaços vazios anteriormente preenchidos pelo pensar e debater questões de interesse geral. ${ }^{6}$

Na pós-modernidade, o Estado encontra-se desafiado em sua matriz. Restam comprometidas a ideia de democracia representativa como fomento à igualdade de todos e realização da vontade geral rouseauniana - quando se sabe que a população vive à mercê dos abusos na publicidade, no discurso e na manipulação políticas - bem como a integridade da soberania, quando se sabe que a internacionalização dos mercados e da interdependência econômica torna inevitável o processo de integração. ${ }^{7}$

A política no contexto da pós-modernidade tem por desafio o respeito à diversidade cultural e discursiva inerente às comunidades políticas. O espaço de concretização da diversidade e do multiculturalismo é o espaço político e somente se efetiva pelo dever de tolerância entre os povos. Destarte, o pluralismo em todas as suas vertentes está implícito na pós-modernidade. ${ }^{8}$

4. Aristóteles. Política. 3. ed. Trad. Mário da Gama Kury. Brasília: Ed. UnB, 1997.

5. Bittar;. Op. cit., p. 15.

6. Idem, p. 33.

7. Idem, p. 28.

8. Heller; Fehér apud Bittar, op. cit., p. 31. 
Liberdade, igualdade e fraternidade fizeram o grito de guerra da modernidade. Liberdade, diversidade e tolerância constituem a fórmula do armistício da pós-modernidade. E com a tolerância transformada em solidariedade, o armistício pode mesmo transformar-se em paz. ${ }^{9}$

Mesmo diante do cenário de esvaziamento da participação política, Bauman afirma que a pós-modernidade não será marcada com o fim da política e muito menos com o fim da história, mas por mais política. Qualquer promessa trazida pelo pós-moderno deverá conter mais política e maior eficácia na ação política individual e comunitária. ${ }^{10}$

Em tempos pós-modernos intensificam-se o projetos de supranacionalização ou integração regional e a ideia de soberania e territorialidade é mitigada em favor do espaço político internacional. Com essa mitigação a noção de cidadania há de ser repensada em seu conteúdo e espaços de expressão, pois a concepção clássica de cidadania que se identifica como um rol de liberdades civis e políticas que possibilitam a participação do elemento povo nos processos decisórios do Estado, se mostra incompatível com a desterritorialização promovida pela globalização. ${ }^{11}$

A supranacionalidade caracteriza-se pela prevalência das decisões comunitárias sobre o interesse individual dos Estados-membros, contando com uma estrutura institucional autônoma e independente e que dispõe de funcionários próprios. As normas produzidas na comunidade são dotadas de primazia e aplicabilidade direta, contando com o auxílio de um Tribunal de Justiça permanente, responsável pela aplicação uniforme das regras comunitárias. ${ }^{12}$

\section{O Parlasul no processo de integração política do Mercosul}

O Mercado Comum do Sul - Mercosul - como um bloco econômico foi instalado em 26.03.1991 quando da assinatura do Tratado de Assunção firmado entre o Brasil, Argentina, Paraguai, e Uruguai. ${ }^{13}$ Entretanto, adquiriu

9. BaUman apud Bittar, op. cit., p. 10.

10. Idem, p. 34.

11. Streck; Morais. Ciência política e teoria do Estado. 5. ed. Porto Alegre: Livraria do Advogado, 2006.

12. Oliveira apud Locateli. Mercosul: adoção do modelo supranacional. Jus Navigandi, n. 53, ano 6, Teresina, jan. 2002. Disponível em: [http://jus.com.br/revista/texto/2486/mercosul-adocao-do-modelo-supranacional]. Acesso em: 20.05.2010.

13. SOARES. Mercosul: direitos humanos, globalização e soberania. 2. ed. rev., atual e ampl. Belo Horizonte: Del Rey, 1999. p. 87. 
personalidade jurídica com o Protocolo de Ouro Preto em dezembro de 2004. Sua estrutura compreende órgãos responsáveis pelas ações administrativas e executivas e um órgão de caráter parlamentar. Atualmente estão associados ao Mercosul a Bolívia, o Chile, a Colômbia, o Equador, o Peru e a Venezuela.

A formação do Mercosul resulta de um processo histórico que se inicia na década de 1940 com a criação da Comissão Econômica para a América Latina (Cepal), contudo, foi na década de 1960 que se inicia a tentativa de formação de um mercado comum com a criação da Associação Latino Americana de Livre Comércio (ALALC) pelo Tratado de Montevidéu. No Ano de 1980, surgiu a Associação Latino Americana de Integração (Aladi) que veio a substituir a ALALC. Neste mesmo ano, segundo a Câmara Internacional de Comércio do Cone Sul os países latino-americanos começam assinar tratados de integração.

O modelo de integração adotado pelo Mercosul foi o da intergovernamentabilidade. Conforme Locateli, esta é caracterizada pela decisão conjunta dos países membros sobre os assuntos internacionais, ou seja, "as decisões resultam exclusivamente do consenso, sua estrutura institucional e seus funcionários dependentes exclusivamente dos interesses dos Estados-partes". ${ }^{14}$ Em decorrência desse modelo adotado, não há uma instância jurídica internacional capaz de regular as relações travadas entre os entes nacionais.

As normas produzidas no âmbito integracionista devem ser internalizadas para produzirem efeitos jurídicos. Não há distinção entre adotar no ordenamento jurídico nacional normas advindas do Mercosul ou aquelas produzidas nas relações com terceiros países. Este procedimento burocrático ocasiona excessiva lentidão, tornando-se empecilho ao desenvolvimento integracionista que busca pela celeridade na aplicabilidade de suas decisões. ${ }^{15}$

\subsection{Da Comissão Parlamentar Conjunta ao Parlasul}

O órgão de caráter parlamentar foi primeiramente denominado de Comissão Parlamentar Conjunta - CPC - prevista no art. 24 do Tratado de Assunção com o objetivo de ser um órgão representativo dos Parlamentos dos Estados-partes no âmbito do Mercosul. ${ }^{16}$

Extrai-se da Ata de aprovação do Regulamento da Comissão Parlamentar Conjunta, de 06.12.1991, que esta comissão era formada por 16 membros de-

14. Melo (1996), apud Locateli. Op. cit., p. 2.

15. Locateli. Op. cit., p. 2.

16. Mercosul. Tratado de Assunção. Disponível em: [www.mercosul.gov.br]. Acesso em: 10.11.2009. 
signados por cada Parlamento Nacional, conforme disposição dos próprios procedimentos internos, chegando ao número de 64 parlamentares dos países signatários do Mercosul. ${ }^{17}$

“Art. 1. ${ }^{\circ}$ Fica estabelecida a Comissão Parlamentar Conjunta do Mercosul, conforme determina o artigo 24 do Tratado de Assunção, assinado em 26 de março de 1991, entre os Governos da República Argentina, República Federativa do Brasil, República do Paraguai e República Oriental do Uruguai, que se regerá por este Regulamento."18

“Art. 2. 'A Comissão será integrada por até sessenta e quatro (64) parlamentares de ambas as Câmaras; até dezesseis (16) de cada Estado Parte, e igual número de suplentes, que serão designados pelos respectivos Parlamentos nacionais, de acordo com seus procedimentos internos." 19

Por força do protocolo de Ouro Preto, em seu art. 25 fora conferida à CPC a função de aceleração da tramitação dos textos normativos do âmbito do Mercosul nos poderes legislativos dos países membros e harmonizar as legislações nacionais com as propostas do bloco econômico. Para isto, a CPC se dividia em seções nacionais atuantes nos legislativos dos países membros promovendo a análise e o devido acompanhamento dos atos normativos que necessitassem de aprovação. ${ }^{20}$

“Art. 25. A Comissão Parlamentar Conjunta procurará acelerar os procedimentos internos correspondentes nos Estados-partes para a pronta entrada em vigor das normas emanadas dos órgãos do Mercosul previstos no artigo 2 deste Protocolo. Da mesma forma, coadjuvará na harmonização de legislações, tal como requerido pelo avanço do processo de integração. Quando necessário, o Conselho do Mercado Comum solicitará à Comissão Parlamentar Conjunta o exame de temas prioritários." 21

A Comissão Parlamentar Conjunta foi um órgão de grande importância para formação do Parlamento do Mercosul na sua atual configuração. Em ou-

17. Mercosul. Ata de aprovação do Regulamento da Comissão Parlamentar Conjunta do Mercosul. Disponível em: [www2.mre.gov.br/unir/webunir/bila/06/2mercosu/mercol4.htm]. Acesso em: 12.11.2009. p. 2.

18. Idem, p. 1.

19. Idem, p. 2.

20. Ribeiro; Martins; Santoro. Parlamento do Mercosul: forma de organização e perspectivas à participação social e às políticas públicas. Observador On-Line, vol. 2, n. 12 .

21. Mercosul. Protocolo de Ouro Preto. Protocolo adicional ao tratado de assunção sobre a estrutura institucional do Mercosul. Disponível em: [www.mercosul.gov.br/tratados-e-protocolos/protocolo-de-ouro-preto-1/]. Acesso em: 12.11.2009. p. 7. 
tubro de 2003, o Conselho de Mercado Comum e a Comissão assinaram um acordo interinstitucional que destacava a importância do reforço da legimitimidade e participação democrática no âmbito do Mercosul, tendo por meio a criação de um parlamento regionalizado que representasse a vontade dos povos do referido bloco econômico. ${ }^{22}$

A instalação do Parlamento do Mercosul, com uma adequada representação dos interesses dos cidadãos dos Estados-partes, significará uma contribuição à qualidade e equilíbrio institucional do Mercosul, criando um espaço comum que reflita o pluralismo e as diversidades da região, e que contribua para a democracia, a participação, a representatividade, a transparência e a legitimidade social no desenvolvimento do processo de integração e de suas normas (BRASIL, 2007, p. 1).

Em dezembro de 2004 foi assinada a decisão CMC 49/2004 para a criação do "Parlamento do Mercosul" como órgão representativo dos povos dos Estados-partes do bloco econômico. À CPC, conforme o art. 2. ${ }^{\circ}$ da referida decisão, foi dada a tarefa de apresentar o projeto de Protocolo constitutivo do Parlasul assumindo também as ações necessárias a sua formalização até a data de 31.12.2006.

A Comissão Parlamentar, composta por representantes dos Parlamentos dos Estados-partes, foi sendo consolidada ao longo de 12 anos até tornar-se o braço político da integração do bloco, estabelecendo os vínculos entre os parlamentos nacionais e os âmbitos decisórios do Mercosul, notadamente o Conselho Mercado Comum e o Grupo Mercado Comum. A criação do Parlamento do Mercosul ocorreu em sessão extraordinária do Congresso Nacional do Brasil, realizada em Brasília, no dia 14.12.2006, e sua sessão inaugural aconteceu no Uruguai, em maio de 2007. Nessa oportunidade, tomaram posse os parlamentares do Mercosul - nove deputados e nove senadores por país - indicados pelos Parlamentos da Argentina, do Brasil, do Paraguai, da Venezuela e do Uruguai. As sessões seguintes foram dedicadas, principalmente, à definição da agenda política do novo órgão e à aprovação de seu Regimento Interno. ${ }^{23}$

Entretanto, o Parlasul foi oficialmente criado em 08.12.2005 com a aprovação do Protocolo Constitutivo pela decisão CMC 23/2005.

22. Ribeiro; Martins; Santoro. Op. cit., passim.

23. BRASIL. Secretaria-Geral da Presidência da República. Mercosul social e participativo: construindo o Mercosul dos povos com democracia e cidadania. Brasília: Ibraes, 2007. p. 17 . 
"Tendo em vista: O Tratado de Assunção, o Protocolo de Ouro Preto e a Decisão 49/2004 do Conselho do Mercado Comum. Considerando: A firme vontade política de fortalecer e aprofundar o processo de integração do Mercosul, contemplando os interesses de todos os Estados-partes. A importância de fortalecer o âmbito institucional de cooperação interparlamentar, para avançar nos objetivos previstos de harmonização das legislações nacionais nas áreas pertinentes e agilizar a incorporação aos respectivos ordenamentos jurídicos internos da normativa do Mercosul que requeira aprovação legislativa. O Conselho do Mercado Comum decide: 'Art. 1 - Aprovar a subscrição do "Protocolo Constitutivo do Parlamento do Mercosul" que se anexa a presente Decisão'. $(\ldots) " \cdot 24$

Essa decisão foi fruto de reuniões da CPC e de dois projetos apresentados pelas seções da Argentina e do Brasil. Sua efetiva instalação realizou-se em 31.12.2006, sendo seu Regimento Interno aprovado pela Disposição 6, de 06.08.2007. ${ }^{25}$

\subsection{Composição e estrutura}

Exposta essa breve nota histórica, passa-se a análise das questões estruturais, principiólogicas e funcionais do Parlasul. Este foi pensado como um parlamento para o Mercado Comum do Sul formado pelos representantes eleitos por voto direto e universal dos povos que compõem o bloco econômico e seus associados. Sua concepção envolve uma transição gradativa que se espera que conduza a esta realidade. ${ }^{26}$

O Parlasul é regido por seu Protocolo Constitutivo, a Decisão CMC 23/2005, assinado pelos Países-partes e por um Regimento Interno aprovado pelos seus parlamentares. Sua estrutura é unicameral, composta por uma assembleia em que estão reunidos os representantes do Brasil, Uruguai, Paraguai, Argentina e Venezuela, como membros efetivos do Mercosul seguidos do Peru, Bolívia e Chile, como membros associados. $\mathrm{O}$ art. 9. ${ }^{\circ}$ do Regimento Interno estabelece o modo de exercício do voto e voz no Parlamento.

24. Mercosul. CMC/DEC n. 23/05. Decisão editada pelo Conselho do Mercado Comum, na cidade de Montevidéu em 08 de dezembro de 2005 aprovando o Protocolo Constitutivo do Parlamento do Mercosul. Disponível em: [www.mercosul.gov.br/normativa/decisoes/2005/mercosul-cmc-dec-no-23-05/mercosul-cmc-dec-no-23-05/?searchterm=CMC/DEC n. 23/05]. Acesso em: 12.11.2009.

25. Ribeiro; Martins; Santoro. Op. cit.

26. Brasil, 2007. Op. cit. passim. 
"Art. 9. ${ }^{\circ}$ Cada Parlamentar tem direito a voz e a um voto.

1. Os legisladores nacionais dos Estados em processo de adesão podem fazer uso da palavra nas sessões do Plenário e nas reuniões das comissões, sem direito a voto.

2. Os legisladores nacionais dos Estados associados podem fazer uso da palavra nas sessões do Parlamento, sem direito a voto." 27

Cada país tem 18 parlamentares ( 9 senadores e 9 deputados), ao total de 144 parlamentares. Para a legislatura que irá de 31.12.2006 a 31.12.2010, os parlamentares serão indicados pelo Parlamento de cada Estado-parte. Para a legislatura que compreende de 01.01.2011 a 31.12.2014, conforme disposição regimental será feita a eleição dos parlamentares por sufrágio direto, universal e secreto de acordo com a agenda eleitoral nacional de cada Estado-parte. ${ }^{28}$

Estruturalmente, o Parlasul é composto por uma Mesa Diretora integrada do Presidente e dos Vice-presidentes do Parlamento, encarregados da condução dos trabalhos legislativos e dos serviços administrativos, suas competências estão estabelecidas no art. 43 do Regimento Interno do Parlamento do bloco econômico, sendo esta Mesa Diretora auxiliada por uma secretaria parlamentar e uma secretaria administrativa que funcionarão em caráter permanente em Montevidéu, sede do Parlasul. ${ }^{29}$

Constam na sua organização, a Secretaria de Relações Institucionais e Comunicação Social, além da Secretaria de Relações Internacionais e Integração. Os parlamentares poderão ainda formar grupos de acordo com suas afinidades políticas. Os grupos serão formados por $10 \%$ da composição do Parlamento quando todos forem representantes de um único país, e cinco parlamentares quando for de composição mista, ou seja, integrarem na sua formação vários países. É vedado ao parlamentar ingressar em mais de um grupo político, sendo constituído o grupo com a devida comunicação a Mesa Diretora. ${ }^{30}$

De suma importância para a estrutura do Parlasul são as comissões, que podem ter caráter permanente, temporário ou especial, consoante as matérias a serem discutidas. As comissões permanentes estão determinadas no Regimento Interno do Parlasul na Seção 3 dos arts. 69 à79 em que se traça a finalidade de cada uma delas. As comissões permanentes são: Assuntos Jurídicos e

27. Mercosul. Regimento Interno do Parlamento do Mercosul. Texto aprovado pela Disp. 06/2007 de 6 de agosto de 2007 alterado pela Disp. 07/2007. Disponível em: [www. merocusul.gov.br]. Acesso em: 12.11.2009.

28. Idem, passim.

29. Idem, passim.

30. Idem, passim. 
Institucionais; Assuntos Econômicos, Financeiros, Comerciais, Fiscais e Monetários; Assuntos Internacionais, Inter-regionais e de Planejamento Estratégico; Educação, Cultura, Ciência, Tecnologia e Esportes; Trabalho, Políticas de Emprego, Seguridade Social e Economia Social; Desenvolvimento Regional Sustentável, Ordenamento Territorial, Habitação, Saúde, Meio Ambiente e Turismo; Cidadania e Direitos Humanos; Assuntos Interiores, Segurança e Defesa; Infraestrutura, Transportes, Recursos Energéticos, Agricultura, Pecuária e Pesca; Orçamento e Assuntos Internos. ${ }^{31}$

As comissões temporárias são aquelas que têm caráter temático, de exceção e curta duração, conforme disposto no art. 80 do Regimento Interno do Parlasul. "As comissões temporárias são criadas para analisar determinado assunto e se extinguem ao término do período parlamentar, ou quando alcançado o fim a que se destinem, ou expirado seu prazo de duração". ${ }^{32}$

Já as comissões especiais assumem caráter temático, tem curta duração, todavia serão criadas em momento excepcionalíssimo, pois decorrem da expressa autorização do plenário nos casos que se perceba a conveniência de sua criação e nas hipóteses regimentais. São criadas pelo Presidente do Parlamento, conforme disposto no art. 81. "O Plenário, nos casos em que estime conveniente, ou que estejam previstos neste Regimento, poderá nomear ou autorizar o Presidente a criar comissões especiais. Pelo mesmo procedimento se criarão as comissões temporárias". ${ }^{33}$

Há também as delegações externas que são criadas para a representação do Parlamento do Mercosul junto aos organismos legiferantes internacionais, terceiros Estados ou blocos econômicos e em uma série de atos públicos, sendo instituída pela Mesa Diretora com a comunicação para o Plenário.

As sessões do Parlamento do Mercosul são públicas em regra, salvo quando forem declaradas de caráter reservado pela maioria absoluta de seus membros, realizadas em Montevidéu, sede do parlamento, podendo ocorrer excepcionalmente em outros lugares, conforme hipóteses traçadas no regimento no seu art. 103.1.

Em caso de guerra, de comoção interna ou de fatos que impossibilitem seu funcionamento na sede, o Parlamento poderá reunir-se, eventualmente, em qualquer outro local, por determinação da Mesa Diretora ou por solicitação da maioria simples dos Parlamentares. ${ }^{34}$

\footnotetext{
31. Idem, passim.

32. Idem, p. 23.

33. Idem, ibidem.

34. Idem, p. 28.
} 
As Sessões são de caráter ordinário, extraordinário e especial. As reuniões ordinárias acontecerão pelo menos uma vez no mês com a finalidade de debater e votar os assuntos da ordem do dia e ao debate parlamentar em geral na forma do seguinte rito determinado pelo art. 123 do citado regimento: (a) discussão e votação da ata da sessão anterior; (b) tomada de compromisso de parlamentares; (c) leitura dos assuntos apresentados; (d) tema livre (hora prévia); (e) debate proposto (questão política); (f) discussão e votação da ordem do dia.

O quórum de iniciação da sessão é de um terço dos membros no qual devem está representados todos os países partes, podendo não ser realizadas nas hipóteses regimentais do art. 118.

Falta de quórum; por motivo de força maior, se assim decidir a Presidência, em consulta à Mesa Diretora. Se constatar que não haverá quórum para realizar a sessão ou existam outros motivos que impeçam sua realização, o Presidente comunicará a todos os parlamentares, com pelo menos 72 horas de antecedência. ${ }^{35}$

As sessões extraordinárias acontecem pela convocação do Presidente, por solicitação do Conselho do Mercado Comum e por decisão da Mesa Diretora ou via requerimento de pelo menos $25 \%$ dos parlamentares, sendo estas convocadas por no máximo 15 dias de antecedência e para apreciação de pauta predeterminada, sendo encerrada quando a mesma estiver exaurida. Por fim temos as sessões especiais que serão convocadas por quórum de maioria simples do plenário; objetivando a recepção de Chefes de Estado, de Governo ou convidados especiais, estas são exclusivas para tal finalidade. ${ }^{36}$

\subsection{Funções e princípios}

O Protocolo Constitutivo do Parlasul reza que este se pauta conforme o princípio do pluralismo e a tolerância como garantias da diversidade de expressões políticas, sociais e culturais dos povos da região. Que suas ações se baseiam na transparência da informação e das decisões para criar confiança e facilitar a participação dos cidadãos, prezando pela cooperação com os demais órgãos do bloco e com os âmbitos regionais de representação cidadã. ${ }^{37}$

Ainda segundo o seu Protocolo Constitutivo, o Parlasul respeitará os Direitos Humanos em todas as suas expressões, repudiará a todas as formas de

35. Idem, p. 30.

36. Idem, passim.

37. Mercosul. Protocolo Constitutivo do Parlamento Mercosul. Aprovado pela Decisão CMC n. 23/2005. Disponível em: [www.parlamentodelmercosur.org/innovaportal/v/4300/1/ secretaria/Sobre_o_Parlamento.html?seccion=2]. Acesso em: 12.11.2009. 
discriminação, especialmente as relativas a gênero, cor, etnia, religião, nacionalidade, idade e condição socioeconômica. Promoverá a promoção do patrimônio cultural, institucional e de cooperação latino-americana nos processos de integração, desenvolvimento sustentável no Mercosul e o trato especial e diferenciado para os países de economias menores e para as regiões com menor grau de desenvolvimento, sendo a equidade e a justiça seus pilares nos assuntos regionais e internacionais, viabilizando sempre a solução pacífica das controvérsias. $^{38}$

O Parlasul tem como funções a preservação do regime democrático nos Estados-partes, a elaboração e publicação anual de um relatório sobre a situação dos Direitos Humanos nos Estados-partes, levando em conta os princípios e as normas do bloco econômico, a realização de reuniões semestrais com o Foro Consultivo Econômico-Social com o objetivo de intercambiar informações e opiniões sobre o desenvolvimento do Mercosul. ${ }^{39}$

Além da organização de reuniões públicas, sobre questões vinculadas ao desenvolvimento do processo de integração, com entidades da sociedade civil e os setores produtivos, o recebimento, exame e encaminhamento aos órgãos decisórios, petições de qualquer particular, sejam pessoas físicas ou jurídicas, dos Estados-partes, relacionadas com atos ou omissões dos órgãos do Mercosul, a emissão de declarações, recomendações e relatórios sobre questões vinculadas ao desenvolvimento do processo de integração, por iniciativa própria ou por solicitação de outros órgãos do Mercosul. ${ }^{40}$

\section{Discussões acerca da natureza parlamentar do Parlasul}

A função típica do Parlamento é legislar. Logo, pareceria lógico que a função típica de um Parlamento Comunitário fosse a de legislar para a Comunidade Política Regional. Nesta ótica, um Parlamento supranacional seria o representante legitimado, dos povos dos Estados-membros, reunidos numa estrutura capaz de criar um direito comunitário e de fiscalizar as ações dos seus integrantes quando as decisões administrativas interferissem na ordem da comunidade política regional. ${ }^{41}$ Entretanto, o Parlasul não possui a função tí-

\footnotetext{
38. Idem, passim.

39. Idem, passim.

40. Idem, passim.

41. Malamud, Andrés; Sousa, Luiz de. Parlamentos supranacionais na Europa e na América Latina - Entre o fortalecimento e a irrelevância sítios. Contexto Inter-
} 
pica de qualquer órgão legislativo, pois emite atos meramente administrativos e consultivos.

A pergunta que se fizeram foi: por que criar um Parlamento do Mercosul? Particularmente em momento em que as instituições parlamentares padeciam de tão profundo descrédito na região, havia o temor de que a iniciativa não fosse bem recebida pela sociedade civil e pelos órgãos da imprensa. Ademais, sabia-se que a um Parlamento do Mercosul não poderia ser atribuída a competência de legislar, em virtude da natureza intergovernamental do bloco. Entretanto, concluiu-se também que a criação do Parlamento representaria passo decisivo para democratizar o processo de integração, ao conferir legitimidade às normas adotadas e possibilitar a sua pronta incorporação ao direito interno dos países membros. ${ }^{42}$

Como percebido pela redação do art. 90 do citado Regimento Interno:

"São atos do Parlamento:
a) Pareceres;
b) Projetos de normas;
c) Anteprojetos de normas;
d) Declarações;
e) Recomendações;
f) Relatórios e
g) Disposições." ${ }^{43}$

Por parecer entendem-se as opiniões emitidas pelo Parlamento sobre projetos de normas que sendo enviadas pelo Conselho do Mercado Comum antes de sua aprovação necessitem de aprovação legislativa em um ou mais Estados-partes, já as recomendações são indicações gerais dirigidas aos órgãos decisórios do Mercosul, as declarações são documentos que fazem referência a manifestações do Parlamento sobre qualquer assunto de interesse público. ${ }^{44}$

As disposições são normas gerais, de caráter administrativo, que dispõem sobre a organização interna do Parlamento e por fim os relatórios que os são

nacional, vol. 27, n. 2. Disponível em: [www.scielo.br/scielo.php?pid=S0102-85292005000200005\&script=sci_arttext]. Acesso em: 18.06.2010.

42. Caetano, G. (coord.). La reforma institucional del Mercosur. Del diagnóstico a las propuestas. Montevidéu: Gefir, 2009. p. 109.

43. Mercosul. Regimento interno... cit., p. 25.

44. Idem, ibidem. 
estudos realizados por uma ou mais comissões permanentes ou temporárias e aprovados pelo Plenário, que contenham análise de um tema específico. ${ }^{45}$

Embora o Parlasul não tenha alcançado o estágio de legislativo supranacional, porque o Mercosul ainda não atingiu tal estágio de integração regional, política e cultural, de modo que o cidadão se sinta um cidadão mercosulino, parte da doutrina acredita no potencial do Parlasul para a consolidação do processo de integração em curso.

Segundo Santoro, apesar de não ter uma função legiferante, não podendo criar o direito supranacional, funcionará como um ponto centralizador dos interesses individuais e coletivos, pois é um local de debates e definição de políticas transnacionais no tocante aos países parte do Mercado Comum do Sul. ${ }^{46}$ Assim, "A integração política não é de natureza decorativa. Ao contrário, o Parlamento foi criado com competência definida e será um instrumento valioso para acelerar a incorporação dos acordos e das normas regionais no ordenamento jurídico nacional". ${ }^{47}$

\subsection{Análise comparativa entre o Parlasul e o Parlamento Europeu}

O Parlasul se inspira na organização do Parlamento Europeu, porém a atuação do Parlamento Europeu é muito maior no tocante às decisões políticas, pois este detém verdadeiro poder legislativo bem definido no seu Regimento interno. Principalmente pelo Instituto da codecisão, introduzido pelo Tratado de Maastricht sobre a União Europeia, em 1992, ampliado pelo Tratado de Amsterdã, em 1999. O que torna o processo legislativo comum. Assim, tanto Parlamento Europeu quanto o Conselho da União Europeia possuem o mesmo peso decisório no que tange ao poder de controle sobre a União Europeia. ${ }^{48}$

A composição do Parlamento Europeu se realiza por meio de sufrágio direito e universal com mandato de cinco anos. Sua primeira legislatura remonta o ano de 1979 tendo como Estados-membros: Alemanha, França, Itália, Holanda, Bélgica, Luxemburgo, Reino Unido, Dinamarca e Irlanda. Órgão representativo dos povos da União Europeia, possuindo Poder Legislativo. O Par-

\footnotetext{
45. Idem, ibidem.

46. Ribeiro; Martins; Santoro. Op. cit., passim.

47. Brasil. Op. cit., p. 17.

48. Parlamento Europeu. Descobrir o Parlamento. Disponível em: [www.europarl.europa.eu/parliament/public/staticDisplay.do?id=146\&language $=\mathrm{PT}]$. Acesso em: 02.12.2009.
} 
lamento Europeu é composto atualmente por 736 deputados eleitos nos 27 Estados-membros da União Europeia. ${ }^{49}$

Estruturalmente o Parlamento Europeu é composto de 20 comissões parlamentares composta por 24 a 76 deputados, 35 delegações cada uma com 15 integrantes sendo de duas categorias: as interparlamentares que tem por função manter relacionamento com os outros parlamentos e as delegações parlamentares mistas que mantém contato com os futuros membros da União Europeia e com os parlamentos dos países associados. Politicamente gravitam em torno do Parlamento Europeu a Conferência dos Presidentes, Mesa, Questores e o Secretariado-Geral. ${ }^{50}$

O Parlamento Europeu não se constitui como mero órgão consultivo como se percebe no Parlasul. O Europarlamento possui tanto capacidade legiferante quanto poder fiscalizatório no tocante ao orçamento da União Europeia. ${ }^{51}$ Ademais, conforme Malamud e Sousa este tem o poder de influenciar a adoção de legislação no âmbito da Comunidade Europeia, pode também iniciar ou instalar comissões de inquérito, questionar os comissários sobre matérias relativas às várias políticas comuns e adotar resoluções e solicitar audiências com a Comissão Europeia. ${ }^{52}$

\section{A participação social e democrática no Parlasul}

Elisa de Sousa Ribeiro et al afirma, com razão, que ainda é deficitária a participação da sociedade civil no âmbito do Parlasul. Há que se fortalecer o espaço regional com a democracia participativa de Paulo Bonavides, única capaz de repolitizar o espaço público e superar a crise de legimitidade da política hodierna, que se estende para além das fronteiras nacionais e atinge os entes de integração política regional. ${ }^{53}$

Despolitizar a legitimidade significa, portanto, matricular o País na escola neoliberal dos globalizadores, com aceitação passiva dos cânones da recolonização (...). Ao contrário, repolitizar a legitimidade equivale a restaurá-la, ou seja, desmembrá-la dessa legalidade onde ela, na essência, já não existe, porque o povo perdeu a crença e a confiança na república das medidas provi-

49. Idem, passim.

50. Idem, passim.

51. Idem, passim.

52. Malamud; Sousa. Op. cit., passim.

53. Ribeiro; Martins; Santoro. Op. cit., passim. 
sórias e na lei dos corpos representativos, cada vez mais em desarmonia com sua vontade, suas aspirações, seus interesses existenciais. Em razão disso, se busca fundar uma nova legitimidade, que só é possível com a repolitização do seu conceito, de todo exequível, se inserirmos a democracia participativa na moldura do regime, da maneira concreta mais ampla, porquanto ao direito constitucional positivo ela já pertence. ${ }^{54}$

Democracia que alcança na atualidade status de direito humano de quarta geração, na ótica do citado autor. O Parlasul deve se tornar um espaço público de participação cidadã para a integração democática das nações do cone sul.

O espaço público poderá ser, futuramente, um dos mais importantes polos políticos de conscientização participativa da cidadania; é sem dúvida a primeira das estradas por onde, nos distritos de sua autonomia social, há de caminhar, em preparação constitutiva, a democracia direta do terceiro milênio. Democracia que assume o status de direito, de quarta geração, direito cuja universalidade e essencialidade compõe o novo ethos que o gênero humano, em sua irreprimível vocação para a liberdade, a igualdade e a justiça, toma por inspiração. ${ }^{55}$

Contudo, no âmbito do Parlasul conta-se ainda com poucas instâncias especializadas para o atendimento e coleta das reivinidicações populares, até na escolha de seus representantes que não se dá por voto direito da comunidade mercosulina, mas por indicação parlamentar de cada Estado-membro.

A falta de participação social democrática no Parlasul é consequência, em parte, de sua origem. Visto que inicialmente foi idealizado pelo Conselho do Mecado Comum, o orgão executivo do Mercosul, na tentativa de resolver a burocracia existente nos processos de aprovação das normas elaboradas pelos orgãos do bloco econômico. Somente depois que se cogitou de transformá-lo em ambiente de participação da comunidade civil. ${ }^{56}$

"Las expectativas respecto al Parlasur son muy altas. Es visualizado como un paso más hacia la creación de instancias supranacionales que permitirá una reflexión política plural de la agenda del proceso de integración regional. Pese a ello existe incertidumbre sobre el real compromiso de los partidos políticos con su funcionamiento (que determina muchas cosas pero fundamentalmente

54. Bonavides, Paulo. Teoria constitucional da democracia participativa: por um direito Constitucional de luta e resistência, por uma nova hermenêutica, por uma repolitização da legitimidade. 2. ed. São Paulo: Malheiros, 2003. p. 288.

55. Idem, p. 279.

56. Ribeiro; Martins; Santoro. Op. cit., passim. 
el sentido y calidad de lo que se haga) así como por su financiamiento y su efectiva inserción en el Mercosur institucional/gubernamental." 57

Desse ponto pode-se concluir que o Parlamento do Mercosul nasce como uma solução desburocratizadora ao invés de legiferante muito menos como espaço de vivência da democracia participativa, o que se torna preocupante, pois como leciona Bonavides:

O substantivo de democracia é, portanto, a participação. Quem diz democracia diz, do mesmo passo, máxima presença do povo nos governos porque, sem participação popular, democracia é quimera, é utopia, é ilusão, é retórica, é promessa sem arrimo na realidade, sem raiz na história, sem sentido na doutrina, sem conteúdo nas leis. ${ }^{58}$

Entretanto, desde a sua implantação, nota-se eventos esporádicos de pressão da sociedade civil aos órgãos decisórios do Mercosul, na tentativa de promover uma participação política maior no seu âmbito. Cite o exemplo, do programa "Somos Mercosul", que objetiva aumentar a integração entre a sociedade e os governos, no espaço do bloco. ${ }^{59}$ A mobilização da comunidade do cone sul e Estados-membros quanto a criação do "el programa 'Somos Mercosur' es principalmente visualizado como una buena iniciativa de articulación entre la sociedad civil y los gobiernos. Permitió 'revelar' una gran diversidad de iniciativas y actores de la sociedad civil que se venían ocupando de los temas regionales". 60

Em que pese ter acontecido à mobilização da comunidade do cone sul e Estado-membros para a criação do Programa "Somos Mercosul", não é o suficiente para caracterizar uma efetiva participação democrática. Necessário se faz efetivar o que está preceituado no seu Protocolo Constitutivo especialmente o art. $6^{\circ}$, I que preceitua que as eleições dos parlamentares serão realizadas pelos cidadãos dos respectivos Estados-partes, por meio de sufrágio direto, universal e secreto. Que cheguemos ao "Dia do Mercosul Cidadão" como está definido no inc. IV do dispositivo citado afim de que realmente haja a verdadeira democracia participativa nestes países que conheceram o autoritarismo e a violência de regimes não democráticos.

Tornemos, outra vez, a Rui, mestre incomparável das grandes verdades políticas e constitucionais do regime, e ele nos traçará com aguda perspicuidade

57. Caetano. Op. cit., p. 173.

58. Bonavides. Op. cit., p. 283.

59. Ribeiro; Martins; Santoro. Op. cit., passim.

60. Caetano. Op. cit., p. 173. 
o perfil da grave crise existencial que ora atravessa o País. Suas palavras lapidares ministram o remédio com que curar esse corpo enfermo que é agora a República Federativa do Brasil.

Disse ele: "Quer-se curar a crise econômica, a crise financeira, a crise administrativa, e se descura a verdadeira crise: a crise do caráter, da consciência e do pudor, a crise moral, social, humana. Esta não se alcançará a sanear, senão saneando o ambiente, ozonando a atmosfera, isto é, acabando com os governos da força e da incapacidade, que, pelo seu princípio mesmo, pela necessidade ingênita à sua natureza, têm de ser, inevitavelmente, governos de injustiça, mentira e corrupção".

Falou Rui e nós lhe completamos o pensamento com acrescentar: governos como o que aí estão, ao apagarem as luzes da eletricidade racionada, já decapitaram primeiro a soberania nacional e espargiram por todo o País as trevas da incompetência, da desídia, do dissídio com a legitimidade, com a ordem moral, com a verdade, com a civilização, com a justiça, com a dignidade da pessoa humana.

Vergonhoso presidencialismo ainda insepulto, e que só a democracia participativa tem pá, ferramenta e braço com que enterrar! ${ }^{61}$

Pecci nos adverte que é indispensável que os governos se abram de maneira decidida a um processo de consultas com a sociedade para redesenhar o modelo de integração do Mercosul, superar suas deficiências e iniciar um processo de defesa das economias e culturas regionais. Aponta a necessidade de iniciativas para melhorar o nível de informação do cidadão comum em cada país membro, centros acadêmicos e imprensa. Devem se ativar espaços orgânicos de participação mais ampla da cidadania organizada ou de caráter institucional. ${ }^{62}$

A verdadeira integração política perpassa pela fixação de metas e projetos políticos comuns entre os países membros, sobretudo em matéria de direitos sociais, onde falta a convergência dos marcos regulatórios. Esta é a tensão a ser resolvida. É hora, sem dúvida, de se fixar um piso de direitos laborais básicos, comuns aos países. Pouco ou nada se tem avançado em matérias de políticas comuns de erradicação do analfabetismo, da carência de redes de saúde. O serviços e uso dos mesmos poderiam ser conectados e otimizados. Programas comuns diante de epidemias importantes facilitariam o conhecimento e a tec-

61. Bonavides. Op. cit., p. 296.

62. PeCCI, 2003. p. 274-275. 
nologia. "No se puede hacer un proceso de integración efectivo com trabajadores enfermos y semianalfabetos". ${ }^{63}$

No entanto, onde a cidadania é incipiente, se as leis e as instituições não forem especialmente boas, todo o conjunto atuará sem sentido evolutivo, desordenadamente. Ocorre uma sucessão de atos e condutas num movimento circular e cumulativo, não levando à melhoria da sociedade, mas, ao contrário, reproduzindo os fatores que geram o atraso. Num quadro como este, o papel das instituições de direito público seria ainda mais relevante que nas sociedades desenvolvidas para romper este movimento e criar condições para o processo da democracia. ${ }^{64}$

O Regimento Interno do Parlasul prevê a realização de audiências públicas e seminários para discussão de assuntos de interesse geral e para inclusão da comunidade mercosulina no âmbito de suas atividades, contudo o déficit de participação é relevante no que se refere à sociedade civil, aos setores produtivos e às organizações não governamentais. Urge que sobre sua atuação se debruce o cidadão mercosulino de forma democrática e participativa.

\section{Conclusão}

Na pós-modernidade, ao passo que se observa certo esvaziamento conceitual da política como espaço público em face de interesses privados de oligopólios econômicos globalizados e à redução da participação política popular; observam-se também processos de integração política, que, não obstante, sua origem econômica, pode contribuir para a realização dos direitos fundamentais do cidadão nas esferas comunitárias regionais que se estabelecem.

Entretanto, deve haver uma ampliação dos espaços de participação popular nestes espaços. Se o Estado não se constitui tão somente de território e governo, mas da comunidade política que o orienta, também os entes políticos regionais ou supranacionais não devem descurar do valor da participação democrática enquanto cabedal da cidadania.

É imprescindível a continuidade da discussão ora levantada no âmbito do Parlasul. A intensificação de sua natureza parlamentar, produtora de um direito supranacional comprometido com a efetividade dos direitos fundamentais e da participação democrática, não obstante a relação de tensão, que por vezes se instala entre estes dois valores.

63. Barbagelata apud Pecci, 2003. p. 277.

64. Dallari; Bucci apud Bittar, 2007. Op. cit., p. 32. 
Faz-se necessária a efetivação do Parlasul como instância fonte de um direito comunitário que regerá as relações entre os povos do Mercosul, em que o mercoparlamentar, legitimamente eleito pelo povo, não fique adstrito à representação de seu país de origem, mas à comunidade mercosulina. Espaço comum que refletirá o pluralismo politico e cultural da região sulamericana, em que se debatam as políticas públicas necessárias à região. Isto contribuirá para a legitimidade democrática do processo de integração, com a inclusão da sociedade civil no debate público.

\section{REFERÊNCIAS}

Achugar, Hugo. A política cultural no acordo Mercosul. Estudos Avançados. vol. 8. n. 20. São Paulo: Instituto de Estudos Avançados da USP, abr. 1994. Disponível em: [www.scielo.br/scielo.php?script=sci_arttext\&pid=S0103-40141994000100021\&lng=pt\&nrm=isso]. Acesso em: 05.05.2010.

Aristóteles. Política. 3. ed. Trad. Mário da Gama Kury. Brasília: UNB, 1997.

Brasil. Câmara dos Deputados. Protocolo de integração cultural do Mercosul. Disponível em: [www.camara.gov.br/Mercosul/Protocolos/INTEGRACAO_ CULTURAL.htm]. Acesso em: 02.12.2009.

BRASIL. Secretaria-Geral da Presidência da República. Mercosul social e participativo: construindo o Mercosul dos povos com democracia e cidadania. Brasília: Ibraes, 2007.

BRASIL. Senado Federal. Subcomissão apresenta relatório sobre Fórum Mundial da Água. Disponível em: [www.senado.gov.br/noticias/subcomissao-apresenta-relatorio-sobre-forum-mundial-da-agua.aspx]. Acesso em: 02.12.2009.

Bittar, Eduardo C. B.; Almeida, Guilherme Assis. Curso de filosofia política. 3. ed. São Paulo: Atlas, 2007.

Bonavides, Paulo. Teoria constitucional da democracia participativa: por um direito Constitucional de luta e resistência, por uma nova hermenêutica, por uma repolitização da legitimidade. 2. ed. São Paulo: Malheiros, 2003.

Caetano, G. (coord.). La reforma institucional del Mercosur. Del diagnóstico a las propuestas. Montevidéu: Gefir, 2009.

IPHAN. Apresentação do anteprojeto Itinerários Culturais do Mercosul. Disponível em: [www.unesco.org.uy/cultura/.../ApresentacaoIPHAN-ppt.pdf]. Acesso em: 02.12.2009.

Locateli, Cláudia Cinara. Mercosul: adoção do modelo supranacional. Jus Navigandi. n. 53. ano 6. Teresina, jan. 2002. Disponível em: [http://jus.com.br/ revista/texto/2486/mercosul-adocao-do-modelo-supranacional]. Acesso em: 20.05.2010.

Malamud, Andrés; Sousa, Luiz de. Parlamentos supranacionais na Europa e na América Latina - Entre o fortalecimento e a irrelevância. Contexto Interna- 
cional. vol. 27. n. 2. Rio de Janeiro: PUC, jul.-dez. 2005. Disponível em: [www.scielo.br/scielo.php?pid=S0102-85292005000200005\&script=sci arttext]. Acesso em: 18.06.2010.

Magalhães Marcos. Comissão do Parlasul debaterá conceito de soberania energética. Agência Senado. Brasília: Senado Federal, 18.05.2009. Disponível em: [www.senado.gov.br/evmmercosul/M007/M0074021.ASP?txtID_PRINCIPAL=516]. Acesso em: 02.12.2009.

Moraes, Alexandre de. Direito constitucional. 23. ed. São Paulo: Atlas, 2008.

Mercosul. Antecedentes do Mercosul. Disponível em: [www.mercosur.int/show? contentid=661\&channel=secretaria\#antecedentes $]$. Acesso em: 30.05.2010.

Ata de aprovação do Regulamento da Comissão Parlamentar Conjunta do Mercosul. Disponível em: [www2.mre.gov.br/unir/webunir/ bila/06/2mercosu/merco14.htm]. Acesso em: 12.11.2009.

CMC/DEC n. 23/05. Decisão editada pelo Conselho do Mercado Comum, na cidade de Montevidéu em 08 de dezembro de 2005 aprovando o Protocolo Constitutivo do Parlamento do Mercosul. Disponível em: [www.mercosul.gov. br/normativa/decisoes/2005/mercosul-cmc-dec-no-23-05/mercosul-cmc-dec-no-23-05/?searchterm=CMC/DEC n. 23/05]. Acesso em: 12.11.2009.

Protocolo Constitutivo do Parlamento Mercosul. Aprovado pela Decisão CMC n. 23/2005. Disponível em: [www.parlamentodelmercosur.org/ innovaportal/v/4300/1/secretaria/Sobre_o_Parlamento.html? seccion=2] . Acesso em: 12.11.2009.

. Protocolo de Ouro Preto. Protocolo adicional ao tratado de assunção sobre a estrutura institucional do Mercosul. Disponível em [www.mercosul.gov.br/ tratados-e-protocolos/protocolo-de-ouro-preto-1/]. Acesso em: 12.11.2009.

. Regimento Interno do Parlamento do Mercosul. Texto aprovado pela Disp. 06/2007 de 6 de agosto de 2007 alterado pela Disp. 07/2007. Disponível em: [www.merocusul.gov.br]. Acesso em: 12.11.2009.

. Tratado de Assunção. Tratado para a constituição de um Mercado Comum entre a República Argentina, a República Federativa do Brasil, a República do Paraguai e a República do Uruguai. Disponível em: [www.merocusul.gov.br]. Acesso em: 10.11.2009.

Oliveira, Rafael Tomás de. Decisão judicial e o conceito de princípio. A hermenêutica e a (in)determinação do direito. Porto Alegre: Livraria do Advogado, 2008.

Parlamento Europeu. Descobrir o Parlamento. Disponível em: [www.europarl. europa.eu/parliament/public/staticDisplay.do? id=146\&language=PT] . Acesso em: 02.12.2009.

Pecci, Antonio V. Por una dimensión social del Mercosur. In: Hugueney Filho, Clodoaldo; CARdim, Carlos Henrique (org.). Grupo de reflexion prospectiva del Mercosur. Brasília: Funag/IPRI/SGIE/BID, 2003. Colección Países y regiones. 
Ribeiro, Elisa de Sousa; Martins, Helena; Santoro, Maurício. Parlamento do Mercosul: forma de organização e perspectivas à participação social e às políticas públicas. Observador On-Line. vol. 2. n. 12. Rio de Janeiro: dez. 2007. Disponível em: [www.opsa.com.br/index.php?option=com_content\&view= article\&id=14\&Itemid=14]. Acesso em: 12.11.2009.

Silva, José Afonso da. Curso de direito constitucional positivo. 29. ed. rev. e atual. São Paulo: Malheiros, 2007.

SiLva, Roberto Luiz. Direito internacional público. 2. ed. rev., atual. e ampl. Belo Horizonte: Del Rey, 2002.

SOARES, Mário Lúcio Quintão. Mercosul: direitos humanos, globalização e soberania. 2. ed. rev., atual. e ampl. Belo Horizonte: Del Rey, 1999.

Streck, Lenio Luiz; Morais, José Luis Bolzan de. Ciência política e teoria do Estado. 5. ed. Porto Alegre: Livraria do Advogado, 2006.

TEMER, Michel. Elementos de direito constitucional. 19. ed. rev. e atual. São Paulo: Malheiros, 2003.

\section{Pesouisas do Editorial}

\section{Veja também Doutrina}

- A convivência dos princípios constitucionais da soberania, integração política e econômica, de Cristiane Dias Carneiro - RDCl 65/293;

- A supranacionalidade e os blocos econômicos, de Eduardo Biacchi Gomes - RDCl 53/310;

- Direitos humanos e Mercosul: do marco regulatório ao papel da justiça, de Jânia Maria Lopes Saldanha - RT 870/11;

- Direitos humanos, democracia e integração regional: os desafios da globalização, de Flávia Piovesan - RDC/37/79; e

- 0 compromisso constitucional da integração, de Pedro Reinaldo Campanini - RDCl $74 / 391$. 